\title{
Promoting Intercultural Competence of Thai University Students through Role-Play
}

\author{
Kanoknate Worawong*, Kanjana Charttrakul, Anamai Damnet
}

Kasetsart University, KamphaengSaen Campus, Thailand

Corresponding Author: Kanoknate Worawong, E-mail: kanoknetnaja@gmail.com

\section{ARTICLE INFO}

Article history

Received: August 18, 2017

Accepted: October 25, 2017

Published: December 30, 2017

Volume: 8 Issue: 6

Advance access: December 2017

Conflicts of interest: None

Funding: None

\section{Key words:}

The CEFR,

Project- based activities,

Role-play,

Intercultural Competence,

Non-Verbal Communication

\begin{abstract}
The current situation of international communication in globalization context requires intercultural competence (IC) to achieve successful communication (Crystal, 2003). Concerning this intercultural competence, non-verbal communication (NVC) plays a key role to indicate the success of having intercultural competence. On the other hand, Thai Ministry of Education (MOE) has launched the CEFR for the country policy in English teaching and learning (Ministry of Education, 2016). The purpose of this paper is to present major results of an investigation of intercultural competence, that is, the NVC. An innovative program implemented in this study is the CEFR and project- based activities (the CEFR-PBA). The study also examines Thai university students' attitude towards this innovative class. This paper discusses the IC students learned from role-plays. The participants of the study were 44 students of third year English Education at a Thai Rajabhat University. Research method applies action research (Burns, 1999) and case study (Yin, Case Study Research: Design and Method, 2003). Data collection gained was from 1) videotape recordings of students' role-play, and 2) the questionnaire. Data analysis for video recordings employed a NVC rating scale evaluated by native-speaker raters; while means, percentage, and SD were used for the questionnaire. Grounded theory's color coding (Strauss \& Cobin, 1990) will be utilized in analyzing the qualitative data from raters' additional comment. Findings revealed students' NVC performance were both appropriate on body movement and position as well as vocalic communication. Moreover, their attitude towards the CEFR-PBA was positive.
\end{abstract}

\section{INTRODUCTION}

This study originated from the current situation of globalization which means the communication among people who has different background of language and culture. Concerning this context, intercultural competence plays an important role and is required as a basic component in intercultural dialogue to promote the mutual understanding. Regarding this intercultural competence, non-verbal communication (NVC) is one of the key factors to indicate the successful of having intercultural competence. However, previous research studies have highlighted how difficult and miscommunication may arise when people with different culture have communicative interaction (Schnell, 2003; Ruthrof, 2015). These problems are most likely to arise in contexts where two cultures are different. In 2001, Council of Europe created Common European Framework of References (CEFR) and many educational institutions applied it for promoting intercultural competence English subjects in designing their curriculum (2001). It was clear that the purpose of integrating intercultural knowledge into English lesson is to avoid the learner's misinterpretation and to promote learners' appropriateness of interactions with speakers who have different L1 and culture. Similarly, in Thailand, this situation brings to the importance of preparing Thai university students to be proficient in both linguistic and sociolinguistic areas of English. As a result, Ministry of Education has launched the CEFR policy to both universities and schools all over the country in integrating those both linguistic and sociolinguistic areas into all language learning (2016).

However, looking closely to Thai students, the results of proficiency exams like ONET revealed low ability of students in English. For example, in 2016 the score of English subject was 27.7 percent lower than the requirement of 50 percent (National Institute of Educational Testing Service, 2016). This inability to reach the standard score of the country reflected national problems in both learning and teaching English. Beside this, according to the researcher' observation, non-verbal communication in classroom practice was found problematic in intercultural exchange at all levels. To confirm this problem, the researcher has investigated English proficienc with a group of students who were talking Culture of Speakers of English Class at the research site (a Rajabhat University) Results showed that English proficie cy did not reach the standard level, and their used of NVC was mostly inappropriate. To be particular, this didn't support the successful communication. As thus, an innovative teaching in promoting intercultural competence seems to be 
required for classroom teaching and learning here. This aims to enhance students to communicate and interact to others who have different language and culture in this context affectively and appropriately. This study aims to promote Thai university students' intercultural competence using an innovative teaching - the CEFR and project-based activities (the CEFR-PBA). Also, it examine student's attitude toward learning through this innovative program. Two research questions addressed in the study are: 1) in what ways do students perform intercultural competence through the CEFR and project-based activities?; and 2) what is the student's attitude toward learning through the CEFR and project-based activities?

\section{Literature Review}

Two major related literatures were reviewed in this study: 1) intercultural competence and non-verbal communication, and 2) attitude toward learning through the CEFR-PBA.

\section{Intercultural Competence}

Intercultural competence refers to the ability to interact between persons from different languages and culture. This is a social cooperative exchange of their knowledge, attitude, and interest about the 'self' and 'otherness' using skills of interpreting to both verbal and non-verbal communication to each other (Byram, 1995; Ruben, 1997; Knapp \& Hall, 2002). Regarding the nonverbal communication (NVC), it plays the key role in successful communication between at least two persons who share different language and culture as NVC has a powerful message value for both encoder and decoder in making the conversation understandable and mutual understanding (Samovar \& Porter, 2001; Knapp \& Hall, 2002)). To outline, NVC has three main significant features. Firstly, it involves codes that are not derived from spoken languages (Triandis, 1994). Secondly, whilst these codes are conventional and form systems that are amenable to interpretation, they can be specific. And the third significant feature is that the meaning of nonverbal codes is influenced by context meaning that the importance and interpretation of nonverbal code cannot be ascribed without the context in which any action happens (Bochner, 1982; Triandis, 1994; Byram, 1995; Ruben, 1997; Gudykunst, 2003; Stier, 2003). Non-verbal communication conveys varieties of meanings mostly in conjunction with verbal communication. In fact, NVC has been characterized to fulfill several distinctive functions in relation to accompanying verbal communication: repeating, complementing, substituting, regulating, and contradicting (Knapp \& Hall, 2002; Ting-Toomy \& Chung, 2005). In an attempt to communicate effectively, certain nonverbal cues in form of eye contact and gaze, facial expression touching, posture and gesture, proxemics, and vocalization are used (Leathers \& Evaes, 1997).

Certain research studies have investigated the role of nonverbal interactants' behavior to facilitate social interactions in a variety of context and situations, the results showed that each context of meaning making has been found to be a major influence on choice and use of communication strategies (Brice \& Brice, 2009; Damnet, 2008). This could be interpreted that NVC is selected and used according to context and it requires skill of interpretation in order to make the conversation be successful. Similarly, Damnet (2008) examined intercultural nonverbal competence of Thai learners using contemporary English films, the results indicates using intercultural nonverbal communication enhance students' competence and facilitate their communicative interaction with English native speakers and avoid miscommunication, misunderstanding, and misinterpreting.

To sum, intercultural competence and the NVC, in particular can be defined as the ability to interact among persons from different languages or culture. Also the NVC is the major role to support the successful communication in international context.

\section{Attitude towards the CEFR-PBA innovative program}

Attitude occurs when a person has experience some events, situations, or phenomena. Gardner (1985) states that attitude is "social psychology's most indispensable concept". Similar to social psychologists, Triandis (1971)and Gardner (1982) claim that attitude employs a directive influence on behavior. This is because someone's attitude toward a target influences the overall pattern of the person's responses to that target. It is obvious that if constructing attitude is indeed of major importance, then there must be some important phenomena of social behavior engaging to attitudes. To explain, attitude is made up of three components: cognitive, affective, and conative; that is, what a person think and feels, and how he or she tends behave toward an object. These components are often interdependent to a certain extent and interact dynamically with the environment. Attitude employs a directive influence on behavior because someone's attitude toward a target influences the overall pattern of the person's responses to that target (Gardner, 1982; 1985; Triandis H. C., 1971).

Relating language learning, Ryan and Giles (1982) present language focus view of attitudes as "any affective, cognitive or behavioral index of evaluative reactions towards different language varieties or their speakers (p. 7)". Attitudes towards a language are often reflects towards members of various ethnic groups. This means that in second language learning, one of the most important attitude factors is the attitude of the learner toward the target language and toward its speakers (Triandis H. C., 1971; Gardner, 1982; Gardner, 1985). Gardner and Lambert (1959) found that attitude and motivation were two factors most strongly associated with learners' L2 achievement. They assert that motivation, attitudes about learning a language are among the determining factors that influence a student's efficiency and must be taken into account for second language learning processes. Regarding SLA, Gardner and Lambert (1959) hypothesize that an individual's reactions to a language variety reveals a great deal about his or her perceptions of the speakers of that variety. As thus, if we know a person's attitude toward the target language community- that is what is he or she think and feels about them- we will have a better chance of being able to predict the way he or she will behave toward them. 
The crucial point in this hypothesis is that a student's attitude towards the target language will influence how successful he or she will be in incorporating many aspects of that language (Gardner \& Lambert, 1959). In addition, it is commonly accepted among scholars that second language leaning involves not only learning skills, or a system of rules, or grammar; but also involves an alternation in self-image, the adoption of new social and cultural behaviors and ways of being, and therefore has a significant impact on the social nature of the learner. Moreover, Spolsky (1969) emphasizes that in second language learning, one of the most important attitude factors is the attitude of the learner toward the target language, its speakers and process of learning.

Impacts from attitudes-both positive and negative- have important role in language learning. As Gardner (1985) describes that L2 learners will positive attitudes toward the target culture and will learn the target language more effectively than those who do not have such positive attitudes. A learner who has positive attitude toward the target language group will exhibit a stronger desire to learn that language as compare with a learner with a negative attitude toward that language. On the other hand, negative attitudes can lead to difficulties in learning a language, particularly when they believe that they cannot learn the new language successful. This is supported by Lennartsson (2008) whose claim about students' belief and attitude that can be obstacle if they believe that they cannot learn the new language successfully. Hence, it could be concluded that attitude plays very important role and is the heart of language learning (Fishman, 1974).

In brief, attitude is the impact of the experiences from behaviors, events, or activities. When good and bad attitude is constructed, then there must be some important phenomena of social behavior happen related to these attitudes. In education field, attitude is the heart of successful or fail in language learning.

\section{METHODS}

This study applied case study (Yin, 2003; 2009) and action research (Burns, 1999) as the major approach to conduct the study. A mixed-methods approach of both qualitative and quantitative research design (Creswell \& Clark, 2011) was used for triangulation of data collection and results. The aims of applying arose from the limitations of all methods for data collection. Jick (1979) states that using multiples methods can diminish some of the disadvantages of certain methods. The common and well-known to mixed methods is the Triangulation Design (Creswell, Plano Clark, Gutmann, \& Hanson, 2003).

In this study, the innovative program; the CEFR Project- Based Activities (the CEFR-PBA) was embedded in normal lesson of English for Presentation Course in English Education Program carried out along with the teaching of regular class taught by teacher-researcher for 12 weeks with four different types of the CEFR-PBA. After the teacher/researcher taught language use in the situations given, next the students watched 2 video clips, and conducted an interview with foreigners. The students then prepared for a role-play.
They performed twice with different topics: 1) Table Manner, and 2) Culture Shock. Participants were $443^{\text {rd }}$ year student while only nine students were selected for data collection from the two role-plays. Research instruments are 1) roleplay video tape recording, and 2) questionnaire. The video tape recording investigated students' non-verbal behavior while the questionnaire was to examine the students' attitude towards the CEFR-PBA. Data collection and analysis employed NVC rating scale evaluated by three native speaker raters. The means score among the three native speakers were used to clarify how much they perform the non-verbal behavior similar to the native speakers. In addition, frequency, means, percentage, and standard deviation were employed for quantitative data. For qualitative data, that is, raters' additional comments on intercultural competence from role-play, Grounded theory (Strauss \& Corbin, 1998) was used.

\section{RESULTS}

Findings are presented into two main parts: 1) the participants' intercultural competence regarding non-verbal communication, and 2) the participants' attitude towards learning through the CEFR-PBA.

\section{Intercultural Competence}

Findings presented here revealed the participants' intercultural competence in two parts. The first part reported a co parison of the means scores of the participants' nonverbal communication between the first and the second role-play. The other part reported qualitative data analysis gained from the three raters' comments.

\section{Quantitative findings}

Data analysis of overall findings concerning students' performance on non-verbal communication indicates two major areas of body movement and position, and vocalic communication from two role-plays. The means score were interpreted and classified into three interval scales: 1) 1.00-1.66 referred to the limited use of the NVC feature compare to what would be expected to be given in the conversation and this leads to unnatural conversation, 2) 1.67-2.33 means the use of NVC features to a level that is acceptable or appropriate. These nonverbal cues make the conversation flow and the NVC performance is similar to English native speakers, and 3) 2.34-3.00 referred to over use of NVC feature compare to what would be expected in the conversation and this leads to unnatural conversation. Results are illustrated in Table 1 below:

Table 1 shows that overall participants performed the limited use of the NVC feature compare to what would be expected to be given in the conversation and this leads to unnatural conversation ( $\overline{\mathrm{x}}=1.49$ ). However, in the second role-play the result showed that in general, all participants performed their NVC performance similar to English native speakers. They performed the NVC features to a level that is appropriate and these nonverbal cues make the conversation flow and natural $(\overline{\mathrm{x}}=1.96)$. 
Table 2 show the student's individual means scores on nonverbal communication rating scale for role-play by English native speakers

Regarding the student's individual means scores on their NVC performance, the results showed that overall, most of the averages mean scores on the second role-play were higher than the first role-play and most of the NVC performances were similar to English native speakers. They used of NVC features to a level that is appropriate. However, when looking at each NVC performance individually, there were some NVC features were overused than the native speakers in the second role-play. They were smile and gazing for Sara $(\bar{x}=2.33, \overline{\mathrm{x}}=2.00)$, hand movement for Anna ( $\bar{x}=2.67)$, and nodding for Bella $(\bar{x}=2.67)$. In contrast, there were some features the participants perform the NVC performance to the level that is appropriate and better than the over used from the first role-play. There were hand movement for Bella $(\bar{x}=2.00)$ and gazing for Britney $(\bar{x}=2.00)$.

\section{Qualitative Findings}

Data analysis from raters' additional comments on nonverbal communication rating scale from the two role-plays from the three English native speakers were analyzed using Grounded theory (Strauss \& Cobin, 1990) and the technique of color coding. Results showed that there were both aspect of appropriate and inappropriate NVC in which the students performed. According appropriateness, there were three aspects emerged. They were; 1) the students had good basic concept of using utensil for having meals, 2) they had natural movement, and 3) body language and gesture were natural and matched the character portrayed in the role-play. However, when taking a look closely at students' NVC three main in-

Table 1. The overall means scores on NVC Rating Scale for Role-Play by English Native Speakers

\begin{tabular}{lcc}
\hline NVC Performance & R1 & R2 \\
\hline 1. Body movement and position & 2.09 & 2.01 \\
1.1 Gestures & 2.10 & 2.06 \\
Hand Movement & 2.15 & 2.04 \\
Nodding & 2.15 & 2.15 \\
Trembling & 2 & 2 \\
1.2 Facial expression & 2.22 & 2.01 \\
Smile & 2.30 & 2.15 \\
Blinking & 2 & 2 \\
Gazing & 2.41 & 2 \\
Frowning and Brow moving & 2.15 & 1.89 \\
1.3 Posture (Showing relaxed or unrelaxed feeling) & 1.96 \\
1.4 Touching behavior & 2.04 & 1.92 \\
2. Vocalic Communication & 2.00 & 1.96 \\
Laughing & 1.48 & 2.18 \\
'um' & 2.04 & 1.93 \\
'ah' & 1.37 & 1.78 \\
'well' & 1.93 \\
\hline
\end{tabular}

Table 2. Student's individual means scores on NVC

\begin{tabular}{lcc}
\hline NVC Performance of Individual Participant & R1 & R2 \\
\hline Student 1 & 1.84 & 2.00 \\
Student 2 & 1.87 & 1.87 \\
Student 3 & 1.60 & 1.73 \\
Student 4 & 1.93 & 1.93 \\
Student 5 & 1.00 & 1.80 \\
Student 6 & 1.27 & 2.26 \\
Student 7 & 1.20 & 2.00 \\
Student 8 & 1.47 & 2.00 \\
Student 9 & 1.27 & 2.07 \\
\hline
\end{tabular}


appropriate aspect immerged, that is, too much gazing for eyes contact, smiling and nodding a lot, and robotic body movement with inappropriate finger pointing and calling. In contrast, the rarely used filler or vocalic communication, and touching behavior when showing concerns in the conversations. The results here indicate that the students required more practice to assert them in reducing their nervousness. In addition, to make the conversation more natural, adding filler or using vocalic communication in conversation should be practiced.

\section{Attitude towards the CEFR-PBA}

Findings revealed the participants' attitude towards the CEFR-PBA in three areas: 1) teacher, 2) learners, and 3) their collaborative learning. The means score were analyzed interpreted into five scales: 1) 4.51-5.00 means the best, 2) 3.51-4.50 means very good, 3) 2.51-3.50 means moderate, 4) 1.51-2.50 means bad, and 1.00-1.50 means the worst as demonstrated in Table 3 below:

Table 3 above indicates that overall the participants have good attitude towards teacher $(\overline{\mathrm{x}}=4.33)$. The highest means score of their attitude was on teacher's methods of evaluation $(\overline{\mathrm{x}}=4.39)$. While the lowest means score was teacher teaching methods $(\bar{x}=4.25)$. Concerning their attitude towards learners: themselves, findings showed that the participants had good attitude towards themselves $(\overline{\mathrm{x}}=4.39)$. The highest means score was on their use of body language $(\overline{\mathrm{x}}=4.43)$. The lowest means score was on their development on language skills ( $\overline{\mathrm{x}}=4.35)$. Relating their attitude towards collaborative learning, findings showed that the participants have positive attitude towards collaborative learning. However, when asking them their negative attitude towards collaborative learning, result showed that they felt the worst with their negative attitude towards collaborative learning, the result was the least $(\overline{\mathrm{x}}=1.48)$.

\section{DISCUSSION}

The findings from the study indicate that the CEFR-PBA innovative program is beneficial in EFL classrooms in two significant areas: 1) role-play activities in enhancing non-verbal communication, and 2) the CEFR-PBA and students' attitude.

Based on the findings, role-play activities could be used to promote intercultural learning and communication in certain ways. Firstly, the findings showed that overall body movement and positions, for example, gestures, facial expressions, postures, and touching were acceptable and appropriate in Roleplay\#1 and \#2 (see Table 1, means $=2.09$ and 2.01 respectively) though frowning and brow movement reveals the least results (means $=2.15$ and 1.89). This could be seen as the L1 culture influencing since Thai people are rather not show this kind of facial expression. However, overall results showed

Table 3. The participants' attitude towards learning through the CEFR-PBA

\begin{tabular}{|c|c|c|c|}
\hline No. & Areas of Attitude & $\overline{\mathbf{x}}$ & SD \\
\hline 1. & Teacher & 4.33 & 0.59 \\
\hline 1.1 & $\begin{array}{l}\text { The participants' attitude towards teacher and teaching } \\
\text { methods }\end{array}$ & 4.25 & 0.58 \\
\hline 1.2 & The participants' attitude towards teaching materials & 4.33 & 0.58 \\
\hline 1.3 & The participants' attitude towards teaching activities & 4.36 & 0.61 \\
\hline 1.4 & $\begin{array}{l}\text { The participants' attitude towards teacher's evaluation } \\
\text { methods }\end{array}$ & 4.39 & 0.6 \\
\hline 2. & Learner & 4.39 & 0.58 \\
\hline 2.1 & $\begin{array}{l}\text { The participants' attitude towards their development } \\
\text { on language skills }\end{array}$ & 4.35 & 0.57 \\
\hline 2.2 & $\begin{array}{l}\text { The Participants' attitude towards their self-directed } \\
\text { learning when participating with the CEFR-PBA }\end{array}$ & 4.37 & 0.58 \\
\hline 2.3 & $\begin{array}{l}\text { The participants' attitude towards their cultural } \\
\text { awareness when participating in the CEFR-PBA }\end{array}$ & 4.42 & 0.57 \\
\hline 2.4 & $\begin{array}{l}\text { The participants'attitude towards their confidence } \\
\text { when participating in the CEFR-PBA }\end{array}$ & 4.39 & 0.59 \\
\hline 2.5 & $\begin{array}{l}\text { The participants' attitude towards their use of body } \\
\text { language when participating in the CEFR-PBA }\end{array}$ & 4.43 & 0.61 \\
\hline 3. & Collaborative Learning & & \\
\hline 3.1 & $\begin{array}{l}\text { The participants' positive attitude towards } \\
\text { collaborative learning when participating with the } \\
\text { CEFR-PBA }\end{array}$ & 4.38 & 0.63 \\
\hline \multirow[t]{2}{*}{3.2} & $\begin{array}{l}\text { The participants'negative attitude towards } \\
\text { collaborative learning when participating with the } \\
\text { CEFR-PBA }\end{array}$ & 1.48 & 0.59 \\
\hline & Total & 4.36 & 0.60 \\
\hline
\end{tabular}


students performed better NVC performance after role-play activities since they have acquired intercultural competence from participating in classroom activity (Krashen, 1988). However, taking a close look at each NVC aspect, there were some NVC behaviors that the students perform inappropriately. This was observed by the raters as nervousness, misunderstanding and their rarely use some verbal cues to make conversations more natural. Regarding this inappropriateness of NVC, the researcher suggested two things when teaching EFL students, that is, knowledge of NVC, and spending more time on students learning and practice. In this case, employing more role-play activities is recommended since only 2 roleplays were implemented in this study. This was because NVC need to reteach and they need more practice since integrating sociolinguistic knowledge into language learning is difficul and is something new to both second language teacher and learner as Weber and Campbell (2003) puts it that it is required to integrate language and culture into language teaching as it is new and crucial to educate second language learners. Acquiring intercultural competence could avoid such problems that may arise from misunderstanding and miscommunication requires more practice and encounter with person who share different language and culture.

The second major findings indicated that the CEFR-PBA innovative program was completely favored by the students. According to the study, the overall results showed the students had good attitude towards the CEFR-PBA (see Table 3, means $=4.36$ ). In particular, they had good attitude towards teaching and learning through this innovative program (means $=4.36$ ). This might be because three main distinctive characteristics of this CEFR-PBA consisting teacher's evaluation methods, active learning and collaborative learning (Fried-Booth, 2002) gave them chances of choice and freedom to learn. In this study, the teacher/research used performance test from role-play to evaluate students' non-verbal communication. This could make the students pay more attention to participate in learning since the method of evaluating has changed from paper test only. Relating the characteristic of active learning, and self- directed learning students had opportunity to learn by doing (Stoller, 2006; Fried-Booth, 1986). In this case, the students had opportunity to perform their NVC in the role-plays as Stroller (2006) states that "Students' autonomy is enhanced especially when they are actively engaged in project planning After they had some experiences, then they can improve by selecting appropriate NVC to use in the role-play. To be specific, students' attitude about their use of body language and cultural awareness reached the highest ranking (see Table 3, means $=4.43$ and 4.42 respectively). However, although the attitude towards teacher and teaching methods was good but it was the lowest (means $=4.25$ ). This means that teacher's techniques and teaching methods should be adapted. Similarly, attitude towards collaborative learning (means $=4.38$ ) demonstrated students' favor in project-based activities (Burns, 1999).

\section{CONCLUSION}

This research paper presents an investigation of intercultural competence and the NVC in particular. The CEFR-PBA innovative program was implemented. Two role-plays were employed to enhance students' using of the NVC. Also, students' attitude towards the CEFR-PBA was examined. The findings emerged as role-play activities could promote language learning and NVC as their NVC showed more acceptable and appropriate. According to these results, integrating language and culture into language classroom teaching and learning is something new for both language learners and teachers. So, having more practice on intercultural teaching and learning and more study on native's non-verbal communication should be considered. Additionally, it might be better to include more experience of learners in interaction in real intercultural situation in EFL classroom context. On the other hand, the results from the attitude questionnaire revealed students like the CEFR-PBA innovative program, particularly, activity-based and collaborative learning.

\section{ACKNOWLEDGEMENTS}

I would like to extend my sincere gratitude to Asst. Prof. Dr. Kanjana Charttrakul and Dr. Anamai Damnet for their devotion in giving me valuable comments to make this study meaningful. I am also very grateful to the National Research Council of Thailand (NRCT) in supporting the scholarship for conducting this thesis project.

\section{REFERENCES}

Bochner, S. (1982). Cultures in contact: Studies in cross-cultural interaction. The social psychology of cross-cultural relations, 1, 5-44.

Brice, A. E., \& Brice, R. G. (2009). Language Development: Monolingual and Bilingual Acquisition. Pearson.

Burns, A. (1999). Colaborative action research for English language teachers. Cambridge: Cambridge University Press.

Burns, A. (1999). Colaborative action research for English language teachers. Cambridge: Cambridge University Press.

Byram, M. (1995). Acquiring Intercultural Competence: A Review of Learning Theories. Intercultural Competence: The Secondary School, 1, 53-69.

Council of Europe. (2001). Common European Framework of Reference for Languages: learning, teaching, assessment. Camebridge: Cambridge University Press.

Creswell, J. W., \& Clark, V. P. (2011). Design and conducting mixed method research ( $2^{\text {nd }} e d$.). USA: SAGE Publication, Inc.

Creswell, J. W., Plano Clark, V. L., Gutmann, M. L., \& Hanson, W. E. (2003). Advance Mixed Methods Research Designs. Handbook of mixed methods in social and behavioral research, 209.

Crystal, D. (2003). English as an International Language. New York: Cambridge University Press.

Damnet, A. (2008). Enhancing Acquisition of Intercultural Nonverbal Competence: Thai English as a Foreign Language and the Use of Contemporary English Language Films. Victoria. 
Fishman, J. A. (1974). Linguistic: The sociology of language. An interdisciplinary social science approach to language in society. American Anthropologist, 4(76), 933-934.933-934.

Fried-Booth, D. L. (1986). Project WOrk (Resource Books for Teachers. Oxford: Oxford University Press.

Fried-Booth, D. L. (2002). Project Work. Oxford: Oxford University Press.

Gardner. (1982). Language attitude and language learning. London: England: Edward Arnold.

Gardner. (1985). Social psychology and second language learnin: The role of attituds and motivation. London: England: Edward Arnold.

Gardner, R. C., \& Lambert, E. (1959, December). Motivation variables in second language acquisition. Canadian Journal of Social Psychology, 4(13), 66-272.

Gudykunst, W. B. (2003). Intercultural communication: Introduction. 163-166.

Jick, T. D. (1979, December). Mixing Qualitative and Quantitative Methods: Triangualtion in Action. Administrative Science Quarterly, 4(24), 602-611.

Knapp, M. L., \& Hall, j. A. (2002). Nonverbal Communication in Human Interaction ( $5^{\text {th }} e d$.). United States: Wadsworth Thomson Learning.

Krashen, S. D. (1988). Second Language Acquisition and Second Language Learning. The modern language journal, 4(73), 440-464.

Leathers, D. G., \& Evaes, M. H. (1997). Successful Nonverbal Communication: Principle and applications. Boston: Allyn and Bacon.

Lennartsson, F. (2008). Students' motivation and attitudes towards learning a second language:-British and Swedish students' points of view.

Ministry of Education. (2016). The Guidelines on English language Teaching and Learning Reforming Policy. Bangkok: Chamjureeproducts Limited.

National Institute of Educational Testing Service. (2016).

Ruben, B. D. (1997, December). Guidelines for Cross-Cultural Communication Effectiveness. Group and Organization Studies, 2(4), 470-479.
Ruthrof, H. (2015). The Body in Language. 2015: Bloomsbury Publishing.

Ryan, E. B., \& Giles, H. (1982). Attitude Towards Language Variation. Journal of Language and Social Psychology, 7.

Samovar, \& Porter. (2001). Communication between cultures (4th $e d$.). California: Wadsworth/Thomson Learning.

Schnell, J. A. (2003). Case studies in culture and communication: A group perspective. New York: Lexington Books.

Spolsky, B. (1969). Attitudinal aspects of second language learning." Language learning. Language Learning: A journal of Research inn Language Studies, 3-4(19), 271-275.

Stier, J. (2003). Internationalization, ethnic diversity and the acquisition of inter-cultural competencies. Journal for Intercultural Education(14).

Stoller, F. L. (2006). Establishing a theoretical foundation for project-based learning in second and foreign-language contexts. 16-24.

Strauss, \& Cobin. (1990). Basics of Qualitative research: Grounded theory procedures and techniques. Newbury Park, California: Sage.

Strauss, A., \& Corbin, J. (1998). Basics of Qualitative Research Techniques and Procedures for Developing Grounded Theory ( $2^{\text {nd }}$ edition). Sociological Research Online.

Ting-Toomy, S., \& Chung, L. V. (2005). Understanding Intercultural Communication (Vol. 1). Oxford University Press: Roxbury Publishing Company.

Triandis, H. C. (1971). Attitude and attitude change. New York: NY: John Wiley.

Triandis, H. C. (1994). Culture and Social Behavior. New York: McGraw-Hill.

Weber, M., \& Campbell, C. M. (2003, September 10). In Others Professional Journal. The Modern Language Journal, 87(3).

Yin, R. K. (2003). Case Study Research: Design and Method. Thousand Oaks: Sage Publication.

Yin, R. K. (2009). Case study research design and methods $\left(4^{\text {th }} e d\right)$. USA: Sage Ltd. 